\title{
Letters
}

Website: bmj.com

Email: letters@bmj.com

\section{The fresh new contract for general practitioners}

$B M J$ should give equal space to opposing views of new contract

EdITOR-Lewis and Gillam write as if the new contract for general practitioners has been accepted by general practice. ${ }^{1}$ This is not the case, and indeed there is a preliminary vote [in June] on whether the framework is acceptable to general practice.

The framework as stated is by no means complete, pensions have not been adequately addressed, the contract has not been priced, and the government still retains the right to unilateral change in any contract.

I hope that the $B M J$ will not threaten its integrity and allow those who are opposed to this contract an equal chance to portray their views as Lewis and Gillam have.

James P Bell principal general practitioner Sunderland SR3 4DX jamesbell@doctors.org.uk

1 Lewis R, Gillam S. A fresh new contract for general practitioners. BMJ 2002;324:1048-9. (4 May.)

One principal buys a new car to celebrate EDITOR-I would like to inform all readers of the $B M J$ that four days after publication of the editorial by Lewis and Gillam I bought

\section{Advice to authors}

We prefer to receive all responses electronically, sent directly to our website. Processing your letter will be delayed unless it arrives in an electronic form.

We are now posting all direct submissions to our website within 24 hours of receipt and our intention is to post all other electronic submissions there as well. All responses will be eligible for publication in the paper journal.

Responses should be under 400 words and relate to articles published in the preceding month. They should include $\leqslant 5$ references, in the Vancouver style, including one to the BMJ article to which they relate. We welcome illustrations.

Please supply each author's current appointment and full address, and a phone or fax number or email address for the corresponding author. We ask authors to declare any competing interest. Please send a stamped addressed envelope if you would like to know whether your letter has been accepted or rejected.

Letters will be edited and may be shortened.

bmj.com

letters@bmj.com myself a brand new Mercedes car to celebrate our proposed new contract. ${ }^{1} \mathrm{I}$ also bought one each for my wife and son. The car dealer wouldn't tell me the price of any of his stock so I said to him: "Never mind about the price, I'll just take those three over there."

Does the GPC (General Practitioners Committee) really think that general practitioners are stupid enough to vote for a completely unpriced contract?

Simon Fellerman principal general practitioner Leeds LS17 7BE

simon@fellerman.co.uk

1 Lewis R, Gillam S. A fresh new contract for general practitioners. BMJ 2002;324:1048-9. (4 May.)

\section{New contract has many failings}

EDITOR-Lewis and Gillam's brief summary of the new contract for general practitioner is somewhat misleading. ${ }^{1}$ Although the proposals allow general practitioners to reduce additional services to reduce their workload, this option is not new: if I choose, I can already stop doing cervical smears or vaccinations, and I can pay others to cover outside normal working hours. Furthermore, most of the pressure on my time comes from what will be defined in the new contract as essential services so the pressure will not change. There is nothing in this contract that will reduce demand.

The proposals are incomplete, and completely unpriced. The new quality targets are interesting at first glance, but a study of the examples given suggests that they will be a bureaucratic nightmare, swiftly degenerating into a vast data collection exercise. This move to "medicine by numbers" will strike at the heart of the doctor-patient relationship

Far from addressing the concerns of general practitioners about workload, pensions, the ability of the government to alter the contract unilaterally, etc, the proposals will do nothing to make general practice an attractive career prospect in the future. Consequently, the recruitment crisis in general practice will continue, and the profession will decline.

By contrast, the Independent GPs Association (www.igpa.org.uk) has proposed alternatives that are clearly priced and address concerns about workload. The proposals would also establish a far clearer link between what general practitioners do and what they are paid.
I am increasingly concerned about the relentlessly positive spin on the new contract. A close study of the proposed framework finds nothing to justify such spin.

Prit Buttar partner

Abingdon Surgery, Abingdon OX14 3LB prit.buttar@ntlworld.com

1 Lewis R, Gillam S. A fresh new contract for general practitioners. BMJ 2002;324:1048-9. (4 May.)

\section{General practitioners are in impossible position}

EDITOR-Perhaps I am unlucky in having a father who remembers the contract negotiations in the 1960s, for I think that general practitioners are about to be ambushed with the proposed new contract. ${ }^{1}$ The headlines look great, but this contract is nothing but spin until it is priced. (Has anyone every tried to build a new kitchen or bathroom without knowing the prices?)

However, more important than price is the structure this contract imposes on general practice. A sideways look at the state education system shows how professionals become in a system that does not focus on individuals. Worse, the new contract will do nothing to reduce demand on its services. Instead there will be a complex and confusing series of electronic mail from all kinds of subcontractors each morning demanding the surgery acts on patients who accessed other care outside surgery hours.

Meanwhile, a practice based contract will leave the few general practitioners willing to invest in the service carrying the can and increasingly looking for a way out, while the new profession (doctor and nurse alike) act like grazing gazelle moving from one salaried post to the next, unhampered by the need to focus on patients or to be centred in the community.

We as general practitioners will be damned if we vote yes and criticised as luddite if we vote no. Perhaps it is understandable that I have a good friend moving into private practice in the summer and another emigrating to Tasmania.

James Cave general practitioner

Downland Practice, Newbury RG20 8UY

jamescave@btinternet.com

1 Lewis R, Gillam S. A fresh new contract for general practitioners. BMJ 2002;324:1048-9. (4 May.)

New contract is con trick

EDITOR-The proposed new contract framework discussed by Lewis and Gillam does nothing for many general practitioners. 
The main problem is that money does not follow workload-the core services. There is no item of service fee for home visits, for example, and no extra payment for patients in residential care whose demands are high.

As ever, those who will benefit are general practitioners who look after patients whose demands are low-professional groups in leafy suburbs and new housing areas. It will do nothing to address the dearth of general practitioners in inner cities or to address the issue of recruitment and retention.

The new contract also seems to imply that doctors can rely on the goodwill of the government for many of its positive aspects to happen. Readers can judge for themselves on that one.

I urge my colleagues to ignore the positive BMA spin and to vote no in June.

John A Glasspool principal general practitioner Victor Street Surgery, Southampton SO15 5SY Churchwarden@btinternet.com

1 Lewis R, Gillam S. A fresh new contract for general practitioners. BMJ 2002;324:1048-9. (4 May.)

\section{New contract will make rural general practitioners' lives even harder}

EDITOR-The new contract discussed by Lewis and Gillam threatens rural general practice when it is in crisis. ${ }^{1}$ Rural general practitioners have been moving practices to avoid the stresses of small rotas for care outside normal working hours.

The new contract on first reading offers some solace for care out of hours. Unfortunately, the dearth of registrars and locums will make implementation of a new system difficult. Some rural areas are also to be excluded from being able to opt out of providing out of hours care.

The income of rural general practitioners is also under threat. A capitation based system will threaten the income of those who hold smaller patient lists.

Additional staff is needed to run rural branch surgeries, which restricts partners' ability to employ secretaries and administrators. As a result, the practice infrastructures of rural practices are less able to deal with the demands of a quality based alternative contract. Any new staff needed for the new contract will apparently be shared with other practices, possibly being employed by primary care groups. This threatens the independence of rural general practitioners.

Income from dispensing is explicitly at risk - a major source of revenue in many rural areas.

Income from temporary residents is also under threat. We as rural general practitioners have increasing demands from a growing number of wealthy elderly people who live an appreciable part of the year in holiday homes. The realities of the recent foot and mouth crisis, and its effect last year on rural tourism seem to have escaped the notice of those drafting this contract. Basing our income from this work on historical data is therefore not in our best interest.
The new contract asks us to make major concessions in changing our funding arrangements but so far offers us nothing concrete in return.

G Rhys principal general practitioner Ty Doctor, Nefyn, Gwynedd LL53 5BL gwion@gwionrhys.freeserve.co.uk

1 Lewis R, Gillam S. A fresh new contract for general practitioners. BMJ 2002;324:1048-9. (4 Mav.)

\section{Contract proposals are fatally flawed}

EDITOR-The editorial by Lewis and Gillam is very optimistic about the future of general practice under the proposed new contract. The fact that two detached academic observers are in favour of it should not be taken as evidence that anyone else is impressed by it. The unanimity of opposition to this contract in the 23 rapid responses posted before mine is noteworthy in itself. ${ }^{2}$ Also the deafening silence about this contract from academic primary care sends out a loud message.

The prosed new contract fails to deal with the key concerns of general practitioners. John Chisholm rightly described the old red book contract as flawed because it basically says: "A GP's gotta do what a GP's gotta do." This new contract does not solve this problem.

Doctors are still to be expected to deal with all manner of symptoms washing up in their consulting rooms (essential services). Consumerism adds an injunction to see everyone within 48 hours whether people are ill or not, just because they want to be seen. General practitioners currently feel swamped by demand. The metaphors used are of trench warfare: we "poor bloody infantry" are being bombarded. We need reinforcements and this proposed contract does not look like providing them. Indeed, it will do little to help recruitment into the speciality.

At present GP principal posts are going begging. These are well paid jobs, and no one seems to want them. Also full time principals at the height of their powers are leaving partnerships and emigrating or working as locums. What is so structurally wrong with general practice that people are leaving partnerships?

Start dealing with these problems, and we might get to a contract that will allow good doctors to work well at a reasonable pace to deliver good quality care to patients. This proposed contract really does not tackle this. It will not deliver enough doctors on the ground to enable delivery of high quality general practice and the government's promises for an improved NHS.

There must be a better alternative waiting to be discovered.

Peter Davies general practitioner

Mixenden Stones Surgery, Halifax HX2 8RQ npgdavies@doctors.org.uk 1 Lewis R, Gillam S. A fresh new contract for general practi-
tioners. BMJ 2002;324:1048-9. (4 May.)
2 Electronic responses. A fresh new contract for general
practitioners. bmj.com 2002 (www.bmj.com/cgi/eletters/ 324/7345/1048; accessed 13 May 2002.)
荻General practitioners quickly came out in force against their fresh new contract. We received 29 responses of varying degrees of hostility by 17 May. All but two respondents were general practitioners, one of the remaining two being a general practitioner in academic primary care, and the other a consultant in ehealth. Twenty seven responses were posted on bmj.com within a week of publication, 18 by 6 May, which, interestingly, was a bank holiday in the United Kingdom.-Sharon Davies, letters editor

\section{Academic medicine}

\section{Academic medicine is still hospital based}

EDITOR-Stewart in his editorial on academic medicine displayed a total lack of recognition that academic medicine includes general practice and other disciplines not included in "teaching hospitals." The largest group of consultants in the NHS work in general practice, not anaesthesia, and maybe Stewart wondered how many general practice trainees were contemplating an academic career.

As someone who started an academic career in 1976 and is about to re-enter the fray, let me offer a different reason why academic medicine is so unpopular. Academic medicine is still dominated by the aristocratic hospital minorities such as internal medicine and surgery, which play such a small part in the modern practice of medicine. Perhaps it is because they have so much time to spare that they can spend their time administering. To become a professor of medicine or surgery now you have to be young, impossibly specialised to the point of non-functionality in any clinical reality zone, and skilled either in the treatment of rats and cats or in plagiarising other people's research through metaanalysis. You then progress to deanship and the task of creating academics in your own image.

The hospital is now an obsolete concept, and most of the departments on which academic medicine is based are as outdated as orders of the garter, the bath, or the chamber(pot). What we need is for academic medicine to provide generic training in the education of students and postgraduates for the cream of those who have shown themselves worthy by surviving in the real world for a few years. The creation of a such a community of scholars is an urgent task and needs to be well funded. If I were in the British government I would not leave the task in the hands of universities because they would be the last people to know what I am talking about.

Campbell Murdoch general practitioner 100A Cannington Road, Dunedin, 9662 New Zealand

cammurd@es.co.n

1 Stewart PM. Academic medicine: a faltering engine. $B M J$ 2002;324:437-8. (23 February.) 


\section{Clinical academic recruitment begins in} clinical departments

EDITOR-Recent publications have highlighted the problems faced by established and aspiring clinical academics. ${ }^{1-3}$ But the role of clinical departments in nurturing or frustrating academic ambitions in specialist registrars, who form a major source for clinical academic recruitment, was not really mentioned.

Clinical academic training usually requires external funding for the salary and project costs of full time research. ${ }^{3}$ But competition for such funding is intense. To have a fair chance of success, time and effort need to be invested in background research, networking, organisation, pilot studies, drafting and revisions of funding applications, and other preparations.

Research time for trainees, in the form of study leave or research days, is not high on the priority list of clinical departments in university hospitals or district general hospitals. They are already struggling with the opposing demands of improving both clinical training and service and guard their manpower allocations jealously. The reduction in clinical time due to changes to working patterns in the new deal (and the forthcoming European working time directive) only exacerbates the situation.

The perception that research training is an unnecessary drain of scarce manpower is reinforced by the finding that most clinical fellows intend to return to clinical practice after fulfilling their interests or aims. ${ }^{1}$ Trainees wanting to do research are sometimes asked to do it in their spare time even though research training should be counted in the total hours worked. Many research related activities cannot be fit to whatever time off is available. Trainees may also be told that taking time to do research compromises their own or other colleagues' clinical training, although other nonclinical activities such as rota administration or teaching, do not similarly detract from anyone's clinical training. Yet others are told that requests for research time cannot be supported on a "value for leave" basis, unless research potential has first been established.

The clinical academic career is difficult enough without this additional layer of frustration. The disincentive is especially powerful since it affects some of the most important years in terms of preparation for entry into an academic career. Whatever time is lost cannot be easily made up within the ordained period and pace of specialist training. Therefore, this approach cannot be optimal for clinical academic recruitment.

Improved clinical academic training structures and clinical academic working patterns do increase the incentives. But they do not actually address the problem of preentry obstruction. A two pronged approach of addressing the manpower concerns of clinical departments and improving support for aspiring clinical academics, should com- plement the measures outlined in the publications.

M W Lim specialist registrar

Northampton General Hospital, Northampton NN1 5BD

michael.lim@ntlworld.com

1 Stewart PM. Academic medicine: a faltering engine. $B M$ 2002;324:437-8. (23 February.)

2 MacDonald R. Survey shows serious shortage of medica academics in the UK. BMJ 2002;324:446. (23 February.) 3 Robinson F. What can you expect from a career in academic medicine? Hospital Doctor 2002;21 Feb:38-9.

MWL's research projects and grant applications are supported by the anaesthetic departments of Kettering and Northampton General Hospitals.

\section{Academy of Medical Sciences responds}

EDIToR-The Academy of Medical Sciences agrees with the diagnoses of the threats to academic medicine made by Stewart in his editorial. ${ }^{1}$ After its formation in 1998 the academy set up a working party under the chairmanship of Professor John Savill to examine academic medical careers. The party's main recommendation was the establishment of a tenure track career pathway for outstanding trainee academics.

Since the publication of the Savill report in April 2000 the Department of Health, the Medical Research Council, and severa medical research charities have committed funds to establish a cohort of new fellowships for clinician scientists and a national committee to monitor these and award a new tranche of academic national training numbers (NTN(A)). ${ }^{2}$ The PPP Foundation has established a series of earmarked fellowships to help develop capacity in disciplines that are particularly threatened, including surgery, radiology, and anaesthesia. More funding is urgently needed.

Mentoring is a key element of career development and has often been a haphazard process in the past. The academy has set up a mentoring scheme to provide independent support and advice to young clinician scientists.

The academy's most recent report has focused on the needs of non-clinical scientists on short term contracts in medical research and highlights the problems of job insecurity, lack of adequate career structures or careers advice, lack of recognition and status, and the problems of remuneration. Failure of employers and funders to tackle these issues may hinder the modernisation of the research infrastructure on which the future development of the medical science base in the United Kingdom depends. Increasingly, the best research is produced by teams rather than by exceptional individuals working largely on their own.

The priority of the NHS is to provide the best possible medical services to the population of the United Kingdom. The support and nurturing of academic medicine must be a key element in attaining this goal. Medical education and training depends on first class teachers and researchers. The practice of evidence based medicine is a goal for everyone who looks after patients. We know, however, very little about many of the most important diseases, and only new research can provide many of the answers.

The academy will continue to play an important part in promoting academic medicine. At its most recent council meeting it agreed to set up a working party to examine impediments to medical research. It also undertook to examine ways of setting up entry level fellowship schemes to encourage bright young doctors to explore research for a year during their early postgraduate years.

Mark Walport registrar

Mary Manning executive director

Academy of Medical Sciences, London SW1Y 5AH apollo@acmedsci.ac.uk

1 Stewart PM. Academic medicine: a faltering engine. $B M$ J 2002:324:437-8. (23 February)

2 Academy of Medical Sciences. The temure-track clinician scientist: a of mist: a new career pathway to promote recruiment into climical academic medicin the report of an Academy of Medical Sciences party chaired by Professor John Savill. London: AMS,

\section{Globalisation and health}

\section{Those concerned with health must} continue to challenge power

EDITOR-Rao argues that trade between unequal partners is better for everyone than no trade at all. ${ }^{1}$ Although specialisation and free trade lead to increased total production, however, the benefits between unequal partners are rarely shared equally. Despite increased production it is not even certain that the population of the weaker economy will benefit; an oversupply of goods produced may lead to lower wages because the price of such goods is set not by benign agreement but by supply and demand.

The doctrine of comparative advantage being of mutual benefit holds only for a static position. ${ }^{2}$ Uganda may have a comparative disadvantage in software design, but if it produces only coffee then its software industry can never develop. Furthermore, overspecialisation in coffee will always leave it vulnerable, including to oversupply.

While oversupply of goods produced by the stronger economy is possible, that economy's strengths generally cushion it better from adversity. These cushions include the flow of interest from poor to wealthy populations, the leverage afforded to creditor populations over the economic and social policies of indebted populations, and the selective and self serving use of tariffs and subsidies by more powerful economies. For these reasons relative inequality remains important.

Feachem admits that current global economic policies have many failings but laments the health community's naivete for going further than he does in its criticism. He claims that the health community uses no, or only circular, citations to support its critique, but he again claims that globalisation has reduced poverty and inequity. In absolute terms, the number of energy deficient people in the world has declined 
marginally in recent decades, but there are several plausible explanations: "globalisation" is only one.

In terms of hard, tradeable currency, such as US dollars, the evidence that global inequality has become more extreme recently is unequivocal. No authority disputes this, though some hide it by referring to income adjusted for "purchasing power parity." ${ }^{5}$ In fact, the global Gini coefficient (using foreign exchange-adjusted currency) increased from an already high $71 \%$ in 1964 to peak at $80 \%$ in 1995 and was $79 \%$ in $1999 .^{5}$ In comparison, Brazil, a country normally considered to be extremely unfair, has a Gini coefficient of little more than $60 \%$.

It is the widening of the gap between rich and poor that so many of the medical profession find unsettling and so many activists find outrageous. The "mainstream" view on globalisation and development that Feacham identifies profits from and supports this inequality. ${ }^{3}$ To paraphrase Virchow, those concerned with health have to find the courage to continue to challenge power.

Colin D Butler PhD student

National Centre for Epidemiology and Population Health, Australian National University, Canberra 0200

colin.butler@anu.edu.au

1 Rao JN. Globalisation and health. BMJ 2002;324:45. (5 January.)

2 Mehmet O. Westernizing the Third World:the Eurocentricity of economic development theories. New York: Routledge, 1999 3 Feachem RGA. Globalisation and health. BMJ 2002;324:45. (5 January.)

4 Melchior A, Telle K, Wiig H. Globalisation and inequality. World income distribution and living standards, 1960-1998. Oslo: Royal Norwegian Ministry of Foreign Affairs; Norwegian Institute of International Affairs, 2000. (Repor No 6B.) (Full text: http://odin.dep.no/ud)

5 Butler CD Inequality, global change and the sustainability of civilisation. Glob Choe Humn Hlth 2000;1:156-72. (Full text: www.baltzer.nl/kaphtml.htm/GLOB1)

\section{Policies must be used to address} disadvantages and inequalities

EDITOR-When looking at the arguments of many proponents of a critical position on globalisation I am sometimes amazed by the lack of consideration for even the most basic principles of (international) economics. Most of us seem to accept that the free exchange of goods and services (free markets and division of labour), as standard operating procedure for our national economies, is the most efficient allocation mechanism for scarce resources. Why does a trade regime become unfair if it tries to promote these same principles internationally?

If it is better as Butler says (in the previous letter and on bmj.com ${ }^{1}$ ) to set the prices for goods by benign agreement rather than by supply and demand why don't we introduce this principle into our national economic policies? Ricardo's theory of comparative advantage describes a static position and does not guarantee an even or fair distribution of the gains from trade (strategic trade policies could take into account shifting comparative advantage, but let's put this aside for the moment).

But why should developing countries not reap the benefits of trade even if these benefits are unevenly distributed? What really is the alternative for Uganda? Will it be able to develop a flourishing information technology industry by closing its borders to imports of Microsoft products? India did not develop its information technology industry through protectionism but through investing into education.

"Trade and industry are the sectors where wealth is produced," says Legge, ${ }^{2}$ but it will be the political sphere that determines how this wealth shall be distributed. Nobody disputes that there will be winners and losers. Inequalities are increasing, and this should be a source of concern (but, apart from sub-Saharan Africa, most developing countries are still better off in absolute terms than they were 10 or 20 years ago). Mainstream economists, including critics like Rudi Dornbusch, agree that on balance globalisation will be beneficial. If this is so why do some of us want to hold up or prevent globalisation instead of trying to reap the benefits and use them to the advantage of those who have not benefited from these gains.

Economic and trade policies are poor instruments for distributional policies as they are highly susceptible to special interests and influence, to the detriment of all of us. It would make much more sense to address disadvantages and inequalities through other measures, such as international development policy, environmental policy, and health policy.

Matthias Schuppe research officer

European Health Forum Gastein, 5630 Bad

Hofgastein, Austria

matthias.schuppe@ehfg.org

1 Butler CD. Free trade, inequality and power. Electronic response to Globalisation and health. bmj.com 2009 (bmj.com/cri/eletters/324/7328/44\#18529; accessed 21 March 2002).

Legge D. Globalisation and health. BMJ 2002;324:44-5. (5 Jegge D.

\section{Treating seasonal allergic rhinitis}

\section{Well designed experiments should have been used}

EdiToR-The publication of a paper by Schapowal and the Petasites Group, purporting to show that butterbur is as good as antihistamines for hay fever and is without their alleged disadvantages, has done the disease and those suffering from it a disservice. ${ }^{1}$ The primary concern of the paper was not the effect of these treatments on the severity of hay fever. To establish this, the essential data are the severity of sneezing, rhinorrhoea, itchy nose and eyes, and nasal congestion before and after treatment. These were given only as diagnostic entrance criteria, and severity of disease became just a secondary outcome measure, derived not from measurement of change in disease state, but from a final, global, clinicians' assessment

The primary outcome measure was not an objective assessment of the disease state but a mishmash of various attributes of mental, physical, and social activity-all secondary consequences of the disease. Since the antihistamine produced the drowsiness and fatigue, as expected by Schapowal et al, in two thirds of those taking it, this would inevitably have had an adverse effect on the physical, psychological, and social wellbeing detected by their primary outcome measure. Thus the spurious primary effect measured is likely to have been an unwanted effect of the drug, totally unrelated to any change in the state of the disease.

This study has absolutely no bearing on the relative therapeutic potency of butterbur and cetirizine in hay fever.

The authors further justify the use of butterbur because it does not produce the drowsiness and fatigue typical of antihistamines. Those effects occurred with all the early antihistamines and many still in use, but they are not intrinsic to $\mathrm{H}_{1}$ blocking action, as was shown for astemizole and terfenadine almost 20 years ago. ${ }^{23}$ There can be no excuse for persistence of this misconception.

Now is not the time for an analysis of the ethos that allows studies such as this and the review process that allows their publication, other than to note that the associated debasement of language into primary and secondary outcome measures is led by industry and drug regulatory authorities; it is not the language of clinical science. What now passes as clinical research demands more of statistical than biological understanding. Perhaps the last contribution of people such as myself is to remind our successors that much of today's understanding was achieved by a clinical science that demanded proof by the elegant simplicity of a few well designed experiments, not the blunderbuss of probability management which lies at the heart of statistical design.

Sam Shuster emeritus professor of dermatology 42 Double Street, Framlingham IP13 9BN Samshuster42@aol.com

1 Schapowal A. Randomised controlled trial of butterbur and cetirizine for treating seasonal allergic rhinitis. $B M$ 2002;324:144-6. (19 January.)

2 Krause LB, Shuster S. The mechanism of action of antipruritic drugs. BMJ 1983;287:1199-200.

3 Krause LB, Shuster S. H1 receptor active histamine not the sole cause of chronic idiopathic urticaria. Lancet 1984;2(8408):929-30.

\section{Trial does not show that there is no difference between butterbur and cetirizine}

EDITOR-The paper by Schapowal et al may be biased, and we question the statistical interpretation of the data. ${ }^{1}$ This is an unusual clinical trial in that it seems to be trying to prove no difference between the treatment arms. We have concerns regarding the methodology and the analysis.

In the usual situation, where a trial is investigating a possible difference between treatments, double blinding is used to prevent bias by patients or researchers. Without knowing which treatment they are 
being given, they cannot consistently overestimate one or other of the treatment effects. But if the hypothesis is that there is no difference between treatments, it is possible to bias the result towards supporting the hypothesis. This happens if one tends to score all patients similarly. This bias could easily result unconsciously on behalf of patients and researchers. Given that the trial on butterbur (a petasite) is conducted by the Petasites Study Group, the researchers may have a strong desire to prove their hypothesis, and this makes them vulnerable to biasing the results unconsciously in this way.

We also question the interpretation of the data. Schapowal et al use a one sided Mann-Whitney rank sum test. They say that significant values mean butterbur is not inferior. The $\mathrm{P}$ values for this test are mostly 0.001 . This seems to imply that butterbur has been shown to be not inferior to cetirizine, with only a $0.1 \%$ chance of this result being wrong.

There are two errors that a trial can make. Type one error is for the trial to show a difference between treatments when, in reality there is no true difference. The risk of this error occurring is quantified by the $\mathrm{P}$ value. The $\mathrm{P}$ value is therefore important when assessing the usual type of trial, which is claiming to show a difference. Type two error is for the trial to show no difference between treatments when, in reality there is a true difference. The risk of this error occurring is quantified by the power calculation. Therefore it is the power of the study-quoted as $80 \%$ - that is crucial in this trial, which claims to have found no difference between treatments. This means that there is a $20 \%$ chance of a type two error occurring, a $20 \%$ chance that there is a difference between butterbur and cetirizine and that the trial results are wrong, (not a $0.1 \%$ chance as implied in the paper.) The trial does not really give any support one way or another to justify the use of butterbur.

Craig A McArthur partner

CMcArthur@GP55624.highland-hb.scot.nhs.uk

Neil Arnott partner

Tweeddale Medical Practice, Fort William, PH33 6EU

1 Schapowal A. Randomised controlled trial of butterbur and cetirizine for treating seasonal allergic rhinitis. $B M$ 2002:324:144-6. (19 January.)

\section{Author's reply}

EDITOR-In response to Shuster, a symptom score is not objective means to verify the status of a disease but purely subjective. The same is true for a quality of life questionnaire. By the means of a symptom score one cannot prove an improvement in the patient's quality of life, which really is the aim of the treatment of the patient, not only of the disease.

Improvement of the patient's quality of life as the main outcome measure in allergic rhinitis was used by many authors to prove efficacy of treatment; this is also true in using the SF-36 health status questionnaire for the effect of cetirizine.

In response to McArthur, to prove noninferiority of a new drug in comparison to a well known, market leading drug is a usual method of clinical drug trials. It is a one sided test in which the active control is virtually worse in the null hypothesis. The drug to be compared has to be better than this virtual value. The advantage of the setting of non-inferiority for a company is mainly that the trial is not as expensive as a trial of equivalence because fewer patients have to be included. The disadvantage is that equivalence cannot be proved by this means; it would need a two sided test of noninferiority or non-superiority. With this in mind our statistical analysis agrees at best with the underlying International Conference on Harmonisation guidelines for statistical analysis and was proved in detail by a statistical peer reviewer. Relevant literature for the shifted null hypothesis has been published. ${ }^{2}$

The good outcome of the trial with the petasites extract versus cetirizine in the setting of non-inferiority paved the way for last year's trial, in which we were able to prove superiority of the petasites extract versus placebo in a double blind randomised study, which will be submitted soon.

Andreas Schapowal ear, nose, and throat surgeon Hochwangstrasse 3, 7302 Landquart, Switzerland Eandreas.schapowal@freesurf.ch

1 Bousquet J, Duchateau J, Pignat JC, Fayol C, Marquis P, Mariz S, et al. Improvement of quality of life in patient with perennial allergic rhinitis with a French version of the SF-36 health status questionnaire. J Allergy Clin Immuno 1194;94:182-8

2 Victor N. On clinically relevant differences and shifted nullhypotheses. Methods Inform Med 1987;26:109-16.

\section{Hyperprolactinaemia caused by antipsychotic drugs}

\section{Endocrine antipsychotic side effects must} be systematically assessed

EDITOR-Wieck and Haddad highlight the fact that hyperprolactinaemia is a common side effect of antipsychotic treatment, but they do not indicate just how often it occurs. ${ }^{1}$

We have found that three quarters of women and one third of men taking typical antipsychotics have prolactin concentrations above the upper limit of the normal range, and there is a highly significant relation between the dose of antipsychotic treatment and prolactin concentrations. ${ }^{2}$ Oestradiol and progesterone concentrations were below the lower limit of the normal range in $85 \%$ of the women.

This evidence supports the authors' suggestion that antipsychotic induced hyperprolactinaemia is linked to clinically important hypogonadism. Furthermore preliminary results indicate that over $40 \%$ of patients taking prolactin raising antipsychotics show osteopenia associated with hypogonadism (A Meaney et al, proceedings of the British Association of Psychopharmacology, Harrogate, 2001). We are currently measuring bone mineral density in patients taking prolactin sparing antipsychotics, and we hope that this study will address some of the evidence needs raised by Wieck and Haddad.

The authors point out that prolactin sparing atypical antipsychotics offer a new management strategy for antipsychotic induced hyperprolactinaemia. However, there are risks associated with reversing hyperprolactinaemia and hypogonadism, as indicated by reports of unplanned pregnancies after patients changed to prolactin sparing antipsychotics. ${ }^{3}$ Many of these patients also experienced a relapse of their psychotic illness after the pregnancy. It is important that patients are counselled about the change in fertility associated with changing to a prolactin sparing atypical and given contraceptive advice.

The national service framework has emphasised that patients with severe mental illness have increased physical morbidity and that assessment should include their physical health. ${ }^{4}$ Wieck and Haddad point to the contribution that endocrine antipsychotic side effects may make to the increased physical morbidity, and these side effects should be monitored.

We recently helped to develop a drug review model that provides patients receiving long term antipsychotic treatment with systematic and periodic assessment of psychopathology, quality of life, and side effects. It is an alternative to the traditional depot clinic style of practice, which often meant that patients took antipsychotics for many years while receiving only ad hoc and limited review. The model represents a move in line with the national service framework towards more proactive patient centred care, and a management approach to the adverse effects of antipsychotics, including the frequently neglected endocrine effects.

Oliver Howes honorary specialist registra Shubulade Smith consultant psychiatrist Institute of Psychiatry, Maudsley Hospital, London SE5 $8 \mathrm{AF}$

sphaoah@iop.kcl.ac.uk

1 Wieck A, Haddad P. Hyperprolactinaemia caused by antipsychotic drugs. BMJ 2002;324:250-2. (2 February.) 2 Smith S, Wheeler M, Murray R, O'Keane V. The effects of antipsychotic induced hyperprolactinaemia on the hypothalamic-pituitary gonadal axis. J Clin Psychopharmacology (in press)

3 Sridharan B, Arshad P, Marcos M. Risk of pregnancy when changing to atypical antipsychotics. $\mathrm{Br} J$ Psychiatr 2002;180:83-4.

4 Department of Health. Mental health national service framework: modern standards and service models. London: $\mathrm{DoH}$ 1999.

\section{Physical complications of mental illness} must be remembered

EDitoR-The physical complications of mental illness, both primary and iatrogenic, tend to be poorly recognised and treated. The editorial by Wieck and Haddad discusses hyperprolactinaemia caused by antipsychotic drugs. ${ }^{1}$ The tendency to focus on extrapyramidal side effects is presumably due to patients' subjective awareness of these 
unpleasant side effects. Relatively silent side effects such as endocrine disturbance tend not to get the same attention.

As well as antipsychotics, other psychotropic medicines such as selective serotonin reuptake inhibitors (with the exception of sertraline) may cause hyperprolactinaemia. ${ }^{2}$ In depressive disorders hypercortisolism mediated by the stress system contributes to osteoporosis. $^{345}$ Depression, as well as cardiovascular disease, must be regarded as a risk factor for osteoporosis.

Many patients with schizophrenia, bipolar affective disorder, or depressive illness take drugs long term, and often combinations of antipsychotic and antidepressant drugs. Pharmacotherapy may confound underlying biological processes acting on the hypothalamopituitaryadrenal axis and accelerate sequelae such as osteoporosis.

Increased awareness of the physical diseases associated with mental illness is essential if optimal care is to be provided.

Sally Winning staff grade psychiatrist

Royal Cornhill Hospital, Aberdeen AB25 2ZH

sally.winning@gpct.grampian.scot.nhs.uk

1 Wieck A, Haddad P. Hyperprolactinaemia caused by antipsychotic drugs. BMJ 2002;324:250-2. (2 February.)

2 Goodnick P, Chaudry T, Artadi J, Arcey S. Women's issues in mood disorders. Expert Opinion on Pharmacotherapy 2000;1:903-16.

3 Deuschle M, Weber B, Colla M, Depner M, Heuser I. Effect of major depression, aging and gender upon calculated diurnal free plasma cortisol concentrations: a re-evaluation study. Stress 1998;2:281-7.

4 Gold PW, Chrousos GP. The endocrinology of melancholic and atypical depression: relation to neurocircuitry and somatic consequences. Proc Assoc Am Physicians 1999;111:22-34.

5 Schweiger U, Deuschle M, Korner A, Lammers $\mathrm{CH}$, Schmider J, Gotthardt U, et al. Low lumbar density in patients with major depression. Am J Psychiatry 1994;151:1691-3.

\section{Consumption of seafood and preterm delivery}

\section{Encouraging pregnant women to eat fish did not show effect}

EDITOR-Should we routinely encourage all pregnant women to consume sea fish or to increase their consumption of sea fish? This is the main practical question inspired by the study by Olsen and Secher. ${ }^{1}$

In 1991-2, in the antenatal clinic of Whipps Cross Hospital in east London, we randomly encouraged 499 pregnant women (before 20 weeks) to increase their consumption of sea fish. Each woman was matched with a control who had had the same number of births. We could not detect any significant effect of our dietary recommendations in the perinatal period in terms birth weight and duration of pregnancy. ${ }^{2}$ The rate of prematurity was $34 / 468$ in the study group $v 44 / 462$ in the control group $(95 \%$ confidence interval 0.45 to 1.2$)$.

We repeated similar studies in three different contexts: a French university hospital (Rennes), a Dutch midwifery practice (Boxtel), and another hospital in east London (Newham). We were not encouraged to enlarge these studies because, once more, significant effects could not be detected in the perinatal period. In the cumulative study group, the rate of prematurity was 23/538 $(4.27 \%)$. In the control group it was $22 / 555$ $(3.96 \%)$.

Olsen and Secher in their study assessed dietary habits that preceded to a great exten the beginning of pregnancy. It is probable that dietary recommendations in antenatal clinics occur too late to have detectable effects in the perinatal period. We should not conclude that such recommendations are useless. We must keep in mind the issues of milk content in highly polyunsaturated fatty acids and brain development. It is noticeable that in the Whipps Cross study the measure of head circumference at birth provided the only detectable difference between the two groups (mean $34.65 \mathrm{~cm} v$ $34.45 \mathrm{~cm}(0.01$ to 0.39$))$.

\section{Michel Odent director}

modent@aol.com

Suzanne Colson research midwife

Paul De Reu research midwife

Primal Health Research Centre, London NW3 2JR

1 Olsen S, Secher NJ. Low consumption of seafood in early pregnancy as a risk factor for preterm delivery: prospective cohort study. BMJ 2002;324:447. (23 February.)

2 Odent MR, McMillan L, Kimmel T. Prenatal care and se fish. Eur J Obstetr Gynecol Reproduct Biol 1996;68:49-51.

\section{Method of cooking should be named}

EDITOR-Thank you for a "fishy" article by Olsen and Secher. ${ }^{1}$ For many years I have been reading papers on the benefit of fish consumption on cardiovascular diseases. Yet no one ever mentions how fish should be cooked.

Are we to swallow live sardine whole? Or eat raw sashimi with snake? Or make it Chinese style sweet and sour? Or pickled herring for breakfast? Or broiled, baked? Surely we are not deep frying fish, like fish and chips, which would defeat the purpose of cardioprotection? Then there are fatty, oily fish, and lean white meat fish, etc. Let us ask our dietician colleagues to clarify, and let us be more specific which fish we should be eating (blue, red, shellfish, etc) and how it should be cooked.

Yasuo Ishida medical director

Healthnet of Cuba, Missouri, 6744 Clayton Road,

St Louis, MO 6311, USA

yishida@earthlink.ne

1 Olsen S, Secher NJ. Low consumption of seafood in early pregnancy as a risk factor for preterm delivery: prospective cohort study. BMJ 2002;324:447. (23 February.)

\section{Grading referrals to specialist breast unit may be ineffective}

EDITOR-Since the two week directive was introduced considerable debate has been surrounding certain aspects of it, especially how appropriate it is for general practitioners to determine urgency. ${ }^{1}$ It was our aim to examine how effective general practitioners' grading of urgency of referrals to our unit has been, comparing the referral grade with the eventual diagnosis.
The database of the breast unit at King's College Hospital retrospectively examined all general practitioners' referrals to the symptomatic breast clinic between April 1999 and December 2000. Altogether 3597 referrals were made, 665 were marked as urgent and 2932 as non-urgent. Sixty two urgent patients and 49 non-urgent patients were subsequently found to have breast cancer. The mean ages were 60.5 years in the non-urgent group and 59.9 years in the urgent group.

It is evident that the two week wait initiative is not ensuring that most patients with symptomatic cancer are seen within two weeks of referral. This is also seen in the British Association of Surgical Oncology's audit $(23 \%$ of cases of cancer in the non-urgent group). ${ }^{2}$ The emphasis on seeing urgent cases within the time has been at the expense of the non-urgent cases. Waiting times in this group have increased to 12 weeks in some units.

What level of cancer cases in the non-urgent group would be considered acceptable? By grading patient referrals, we are creating a two tier structure, with patients in the non-urgent group waiting longer periods for diagnosis and treatment. For patients with cancers in this group the delay can be critical. The government's initiative should be applauded for ensuring a uniform standard, but its basis of using urgency of referral has meant unacceptable delays to some patients with breast cancer as well as delay with anxiety to those without. As no grading system is perfect, the only way of guaranteeing that all patients with breast cancer are seen within two weeks is by seeing all the referrals in this period.

This has become achievable at our unit, mostly through organisation and not resource allocation; this is dependent on flexibility and forward planning. The King's breast unit is part of a cancer collaborative that uses action research to introduce changes to improve effectiveness. This has been well summarised by an editorial by Smith and encapsulated by an aphorism originating from Mark Murray-"doing today's work today."3

S Thrush specialist registrar

Kent and Sussex Hospital, Tunbridge Wells

TN4 8AT

G Sayer specialist registrar

Scott-Coombes consultant surgeon

J V Roberts consultant surgeon

King's College Hospital, London SE5 9RS

1 NHS Executive, Breast cancer waiting times-achieving the two-zueek target. London: Department of Health, 1998. (Health Service Circular 1998/242.)

2 Sauven P. Specialists, not GPs, may be best qualified to assess urgency. BMJ 2001;323:86

3 Smith J. Redesigning health care. BMJ 2001;322:1257-8.

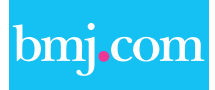

Rapid responses

Correspondence submitted electronically

is available on our website 